\title{
Mapeamento das áreas degradadas por poços de petróleo por meio da aerofotometria na região produtora de Mossoró-RN
}

Mapping of areas degraded by oil wells through aero photometry producing region in Mossoró-RN

\author{
Alexsandro Albino S. Oliveira'; Carlos Enrique de Medeiros Jerônimo² \\ 1:2Engenharia de Petroleo e Gás, Universidade Potiguar, Natal-RN, Brasil
}

\section{Resumo}

Gerenciar o mapeamento do Município de Mossoró-RN, com enfoque nas áreas degradadas por poços de petróleo a partir do estudo por aerofotometria utilizando o Google Earth como ferramenta fundamental, criando uma base de dados para ter uma estimativa da área degradada, as técnicas de processamento digital de imagens, além de permitirem analisar uma cena nas várias regiões de estudo, também possibilita a integração de vários tipos de dados, devidamente registrados através desses disso foi possível criar tabelas com tratamento estático para melhor compreensão

Palavras-chave: Degradação, Mapeamento, Aerofotometria.

\begin{abstract}
Manage the mapping of the Municipality of Mossoró-RN, focusing on degraded by oil wells from the study by aerophotometry using Google Earth as a fundamental tool areas, creating a database to have an estimate of the degraded area, processing techniques digital images, besides allowing to analyze a scene in the various regions of study also enabled the integration of multiple data types, duly registered through that it was possible to create tables with static treatment for better understanding.
\end{abstract}

Keywords: Degradation, Mapping and aerophotometry. 


\section{INTRODUÇÃO}

O uso de combustíveis fósseis tornou-se indispensável para diversos campos da economia. Dentre esses recursos, o petróleo apresenta-se como o que possui a utilização mais significativa, já que deixou de ser apenas uma fonte energética e passou a desempenhar um papel de destaque como matéria-prima de diversos bens de consumo e de produção. No entanto, deve-se considerar que a indústria do petróleo (processos de extração, transporte, refino e consumo) gera riscos socioambientais consideráveis, visto que todo e qualquer tipo de exploração e transformação dos recursos naturais gera poluição e impactos sobre o meio físico, social e econômico².

O município de Mossoró, por sua vez, abriga o Campo Canto do Amaro, descoberto em 1985, e alvo dos primeiros investimentos no setor no estado por parte da Petrobras. Este campo é o primeiro em produção (terrestre) de petróleo no Rio Grande do Norte, ilustrando a importância de Mossoró para o setor petrolífero potiguar ${ }^{1}$.

Diante disso, o Rio Grande do Norte é o $3^{\circ}$ maior produtor de petróleo do Brasil ${ }^{2}$.

Pode-se dizer que áreas degradadas são aquelas onde se encontram solos pobres e erodidos, baixa produtividade, instabilidade hidrológica e diversidade biológica reduzida ${ }^{3}$.

No caso da indústria do petróleo, os principais impactos ambientais são caracterizados pela degradação e poluição dos solos, respectivamente, com a retirada da vegetação e preparo do solo durante a instalação e exploração nos poços em terra e derramamentos de óleo; do ar, representados pelas emissões de poluentes durante o processo de refino; e de mares, resultado de escapes naturais de óleo, acidentes em poços perfurados no mar, vazamento ou derramamentos de óleo, naufrágios, colisões ou despejo de rejeitos do processamento industrial (MATOS, 2010). Sob o ponto de vista socioeconômico, a atividade petrolífera apresenta-se como divergente. Mesmo que, por um lado, represente desenvolvimento, o benefício acaba por restringir-se apenas às grandes empresas administradoras e para a pequena parcela da sociedade que é favorecida com os royalties. Enquanto a outra grande parcela populacional não desfruta, nem de longe, do lucro que a atividade pode trazer ${ }^{4}$.

A abordagem da indústria do petróleo deve considerar as características geoambientais da área de influência. O estudo deve ser reforçado em áreas onde os efeitos da produção e explorações do petróleo podem ser maximizadas, acarretando impactos negativos sobre o meio ambiente. No território Mossoroense, as áreas submetidas ao fenômeno da desertificação e o ambiente costeiro do estuário do rio Apodi-Mossoró são exemplos de áreas susceptíveis à degradação por esse tipo de atividade econômica. ${ }^{3}$

O trabalho teve como objetivo mapear a área degradada pela presença de poços de petróleo em Mossoró por meio de aerofotometria, tanto para discutir a eficácia da possibilidade de meios de recuperação, quanto para induzir novos estudos, no campo prático, sobre a degradação de seu campo, atrelando-as aos parâmetros da Sustentabilidade. ${ }^{3}$

Aerofotometria é o nome dado ao método de obtenção de dados topográficos por meio de fotografias aéreas, geralmente, com o fim de mapeamento. Assim como na foto-interpretação as informações quantitativas estão registradas em cores (bandas) captadas através de uma câmera fotográfica ou métrica que capta a energia irradiada/refletida pelos objetos ${ }^{6}$.

O município de Mossoró se destaca no Estado do Rio Grande do Norte como uma das regiões de grande potencialidade econômica, tendo em vista que o mesmo detém dois recursos naturais de grande valor econômico no atual mercado: o sal e o petróleo. Esses juntos e com a agroindústria são referenciais da economia de Mossoró. O setor industrial tem vivido ciclos diferenciados. A vocação industrial extrativista de Mossoró a coloca hoje no pódio como principal produtora de sal e de petróleo (em área terrestre do país). Contribui com $50 \%$ a $98 \%$ da produção salineira do país e mais de 3.500 poços de petróleo, produzindo $110 \mathrm{mil}$ barris/dia. ${ }^{5}$

A Bacia Potiguar se destaca pela sua expressiva importância na economia regional e nacional por seus recursos naturais, pode ser medida pelas atividades exploratórias e de extração de petróleo e gás natural. Apresenta uma produção diária de 110.000 barris de petróleo, e gás natural quase seis milhões de metros cúbicos e pela salineira que respondem cerca de $92 \%$ da produção nacional de sal, cujo índice pode chegar a $98, \%$ no auge da produção. A referida bacia é a segunda maior produção de óleo e é a maior produção de óleo em terra atualmente no Brasil ${ }^{5}$. 
Neste trabalho é feita uma estimativa das áreas degradadas pela exploração do petróleo na região de Mossoró, mediante a utilização dos recursos de analises aerofotogramétricas.

\section{MATERIAIS E MÉTODOS}

A metodologia baseou-se nas observações de campo, por meio da aerofotometria na região produtora de Mossoró-RN, dos poços, das linhas de produção e das estações receptoras com ajuda dos softwares Google Earth (um programa de computador desenvolvido e distribuído pela empresa americana Google, cuja função é apresentar um modelo tridimensional do globo terrestre, construído a partir de mosaico de imagens de satélite obtidas de fontes diversas, imagens aéreas) ${ }^{7}$. $\mathrm{Na}$ área de estudo observaram-se fortes marcas da atividade humana no processo da degradação das terras onde a dinâmica natural tem sido negligenciada. $\mathrm{Na}$ avaliação das imagens definiram-se três níveis de degradação das terras: Moderado, Grave e Muito Grave. As exposições de solos nus são, no geral, áreas de empréstimo de terras usadas para construção das bases das estruturas de exploração do petróleo, de estradas, de aterros e outras construções, onde não existem trabalho de conservação e recuperação, e os processos erosivos progridem rapidamente formando-se desde sulcos até voçorocas profundas. Apesar de ser uma área de uso agrícola, com predominância da pecuária extensiva, o principal agente degradador das terras tem sido a exploração petrolífera ${ }^{9}$.

A área de pesquisa será procedida de um mapeamento preliminar de feições geológicas, por aerofotometria através do software Google Earth, fazendo um mapeamento detalhado das áreas com degradação pela presença de poços de petróleo, considerando os padrões fotográficos identificados pela variação dos matizes de cores, e pelos elementos textuais de relevo e drenagem, como também a partir dos dados do processamento por fotografias Aéreas que serão processadas diretamente no computador.

Serão realizadas as avaliações destes dados visando se identificar às equivalências de escalas, tipos de coordenadas geográficas, qualidade das digitalizações e principalmente as compatibilidades dos arquivos, para se trabalhar em uma plataforma única de softwares.

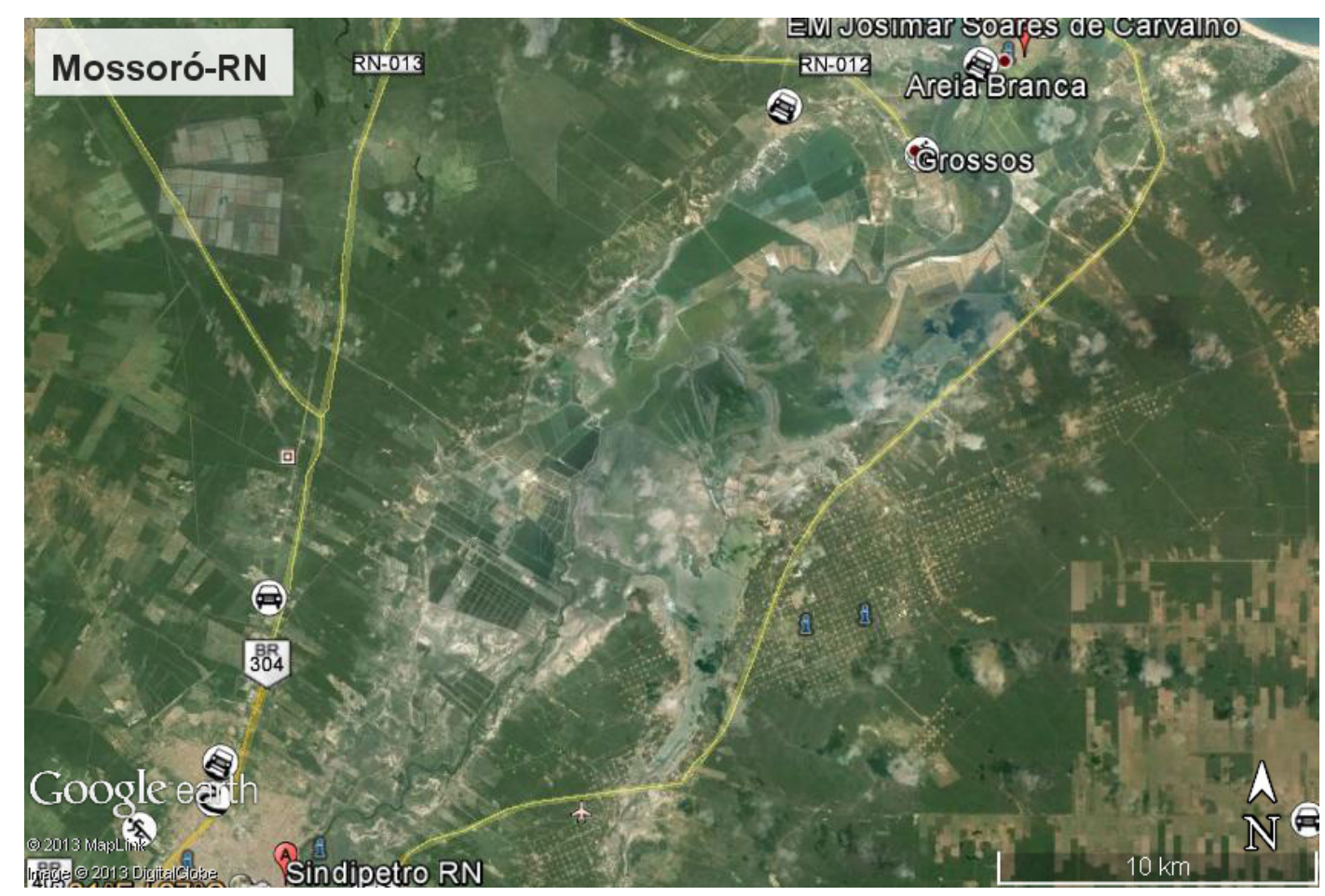

Figura 1 - Mapa da cobertura por Aerofotometria de Mossoró - RN 
Observou-se que o processo de erosão na área envolve drasticamente não somente as questões da mudança climática global e geológica, mas mostra ter uma relação direta com as atividades humanas na região, como a exploração do petróleo.

Ainda como fontes de pesquisas, a coleta de dados valeu-se de análise documental, importante principalmente pelo acesso a alguns relatórios e manuais de procedimentos internos ${ }^{9}$.

Define a análise documental como uma consulta a documentos internos da instituição ou setor pesquisado, a fim de coletar dados que facilitem o entendimento do que está sendo pesquisado. A autora cita os tipos de documentos que podem se consultados: "devem ser pesquisados documentos que reflitam a natureza, a filosofia, a política da empresa, tais como: regimentos, estatutos, planos de cargos e carreiras, organogramas, contratos sociais". ${ }^{10}$

\section{RESULTADOS E DISCUSSÃO}

Apesar da população mossoroense está concentrada na Zona Urbana, com aproximadamente $93 \%$ do total, a Zona de Interesse Rural é mais extensa, compreendendo uma porção bem maior do território municipal. Dessa forma, todos os objetos e sistemas de ações inerentes à atividade petrolífera se localizam fundamentalmente na área denominada de Zona de Interesse Rural. ${ }^{11}$

Como podemos constatar na citação anterior da lei do plano diretor, a qual define a Zona de Interesse Rural, não há alusão alguma à atividade petrolífera, sendo citada apenas a atividade agropecuária, a qual deverá ter suas dinâmicas preservadas. Portanto, a indústria do petróleo em Mossoró aparece no campo como uma atividade atípica desse meio, principalmente nos casos em que a extração ocorre em meio a uma comunidade ou mesmo em um sítio. Nesse contexto, as atividades tradicionais cedem espaço e/ou convivem com uma atividade do segundo setor, altamente tecnificada em seus instrumentos e operações, distribuída ao longo da zona rural de Mossoró. ${ }^{11}$

A espacialidade da indústria do petróleo no município de Mossoró apresenta características diferenciadas de outras áreas produtoras de petróleo. Essa diferenciação deve-se a grande extensão do campo petrolífero, que inclusive é considerado o maior do país em terra. ${ }^{11}$

Existem cerca de 3.500 poços de petróleo em atividade no município de Mossoró, segundo dados da prefeitura, esses poços compõem a estrutura produtiva e ocupam áreas de povoados, sítios e fazendas. Dessa forma, podemos observa a perfuração de poços ao lado de casas, escolas e praças. Além da presença de linhas de vapor com $70^{\circ}$ graus de temperatura que passam por dentro dos povoados e as linhas elétricas de alta tensão. ${ }^{11}$

Junto a esses equipamentos existe a necessidade de implantação de estradas, picadas e clareiras para o desenvolvimento da produção. Esses objetos técnicos que são usados para o desenvolvimento da estrutura produtiva associados aos sistemas de ações se apropriam do espaço. Desse modo, é possível dizer que a atividade petrolífera possui uma dinâmica territorial própria, que pode variar no espaço e no tempo, pois se trata de uma atividade que se encontra em constante mutação tanto na zona rural quanto na zona urbana do município de Mossoró. ${ }^{11}$

Com a formação do território pela cadeia produtiva da indústria do petróleo, alguns conceitos geográficos são colocados em evidência, como o conceito de territorialidade que "refere-se ao conjunto de práticas e suas expressões materiais e simbólicas capazes de garantirem a apropriação e permanência de um dado território por um determinado agente social, o Estado, os diferentes grupos sociais e as empresas". ${ }^{12}$

Uma outra abordagem, constituí fundamentalmente no fato das pessoas terem consciência de que fazem parte do território e que estão integrados a ele. Como destaca, "a territorialidade corresponde ao processo subjetivo de conscientização da população de fazer parte de um território, de integrar ao território". ${ }^{13}$

Diante do quadro exposto, observamos que atualmente a atividade petrolífera no município de Mossoró desenvolve práticas, expressões materiais e simbólicas capazes de manter o território. Ressaltamos que, parte das áreas que atualmente são ocupadas pela cadeia produtiva da indústria petrolífera, constituíam-se, anteriormente, em espaços apropriados exclusivamente pelas atividades agrícolas e pastoris do município. 
Dessa forma, os objetos técnicos e os sistemas de ações dessa indústria apropriam-se de áreas dispersas, ao longo do município, para o seu desenvolvimento, e, por conseguinte, amplia o território estabelecido pela indústria petrolífera. Com a expansão do território, dialeticamente, amplia-se a territorialidade e consequentemente provoca a desterritorialidade das áreas submetidas a tal indústria. Daí a necessidade de compreender o território e, consequentemente, as suas derivações, como categoria temporária, de vez que no espaço e no tempo nada é permanente, tudo está em constante transformação. É preciso atentar também para as questões ambientais que emergem com o processo de exploração e produção do petróleo, as quais são por vezes esquecidas em meio à ideia de progresso e desenvolvimento que cercam a indústria petrolífera. ${ }^{14}$

Apesar do desenvolvimento observado na região, as atividades econômicas desenvolvidas nas proximidades dos corpos d'água vêm acarretando transformações na paisagem estuarina. Os mangues, definidos como área de preservação permanente por legislação ambiental nacional, após a implantação das salinas há mais de 50 anos, foram devastados e, hoje grande parte dessas áreas encontram-se ocupadas pelos viveiros de camarão. A área de caatinga, começa a ser ocupada também pela atividade da carcinicultura e principalmente pelo petróleo. Consequentemente a utilização de agrotóxicos nas áreas agricultáveis de fruticultura e o comprometimento do aquífero pelo uso descontrolado da água; a exploração intensiva pela Petrobrás com desmatamento indiscriminado, vazamentos de óleo, enterro de refugos sem o menor cuidado ambiental e lançamento de dejetos no Rio Mossoró, vêm contaminando vastas áreas e degradando o ambiente estuarino e favorecendo o processo de desertificação. ${ }^{15}$
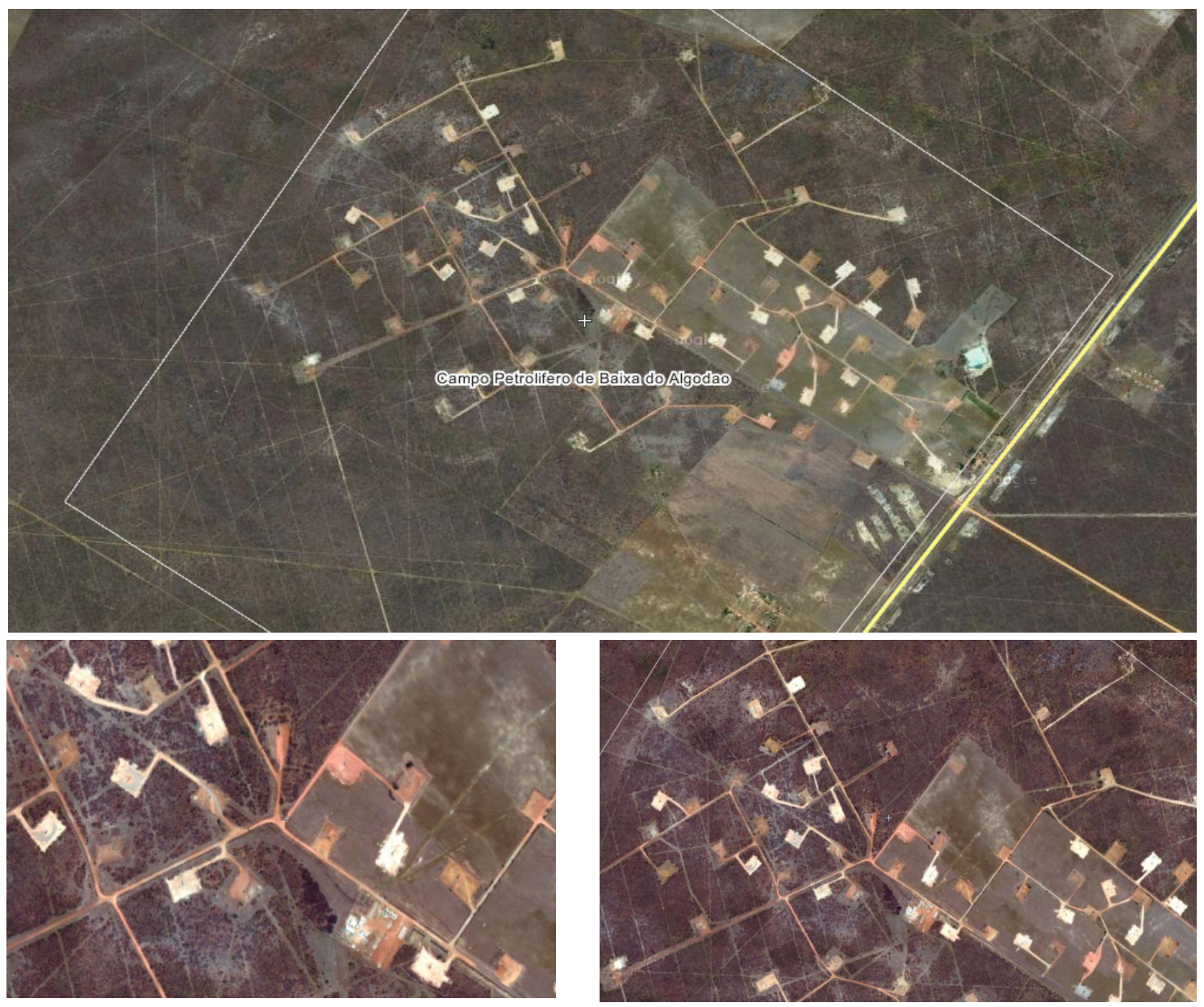

Foto 02: Imagem Google Earth (Campo Petrolífero de Baixa do Algodão) - Da área do Campo petrolífero de baixa do algodão, evidenciando as fortes áreas de exploração de petróleo. Nos quadros fotos ampliadas, visualizando impactos ambientais observados na área de exploração de petróleo. 


\title{
Calculo de Área - Campo Petrolífero de Baixa do Algodão
}

\author{
Área $=3,186 \times 2,992$ \\ Área $=9,533 \mathrm{~m}^{2}$
}

Uso e Ocupação do Solo: É considerado desde o início do procedimento metodológico alicerce básico para a definição e o mapeamento dos demais Planos de Informação. As informações foram levantadas a partir de imagem do Google Earth.

\section{Risco a degradação das terras - Canto do Amaro}

$\mathrm{Na}$ área de estudo foram observadas as fortes marcas da atividade humana no processo de degradação das terras onde a dinâmica natural foi negligenciada. A vegetação nativa praticamente não existe mais. Grande parte da área hoje é ocupada pelas invasoras, como a jurema, a catingueira e o pereiro. As cactáceas são pouco representadas. Em vários pontos os solos estão expostos sob influência da erosão hídrica e eólica, onde a fertilidade está altamente comprometida não permitindo o desenvolvimento nem de gramíneas, e a rala vegetação presente nestas áreas são caracterizadas pelo nanismo. Além da extração de petróleo, na área de estudo foram observadas atividades agrícolas, principalmente a pecuária extensiva, a exploração de calcário e dos solos como material de empréstimo e salinas. ${ }^{16}$

A avaliação da degradação das terras na região do campo petrolífero Canto do Amaro foi realizada a partir de imagens Google Earth. A imagem Google Earth (Figura 3) mostra que em boa parte da área de estudo se desenvolve uma vegetação mais ou menos densa, principalmente na porção centro nordeste. As áreas de solo expostos estão representadas por tons claros.

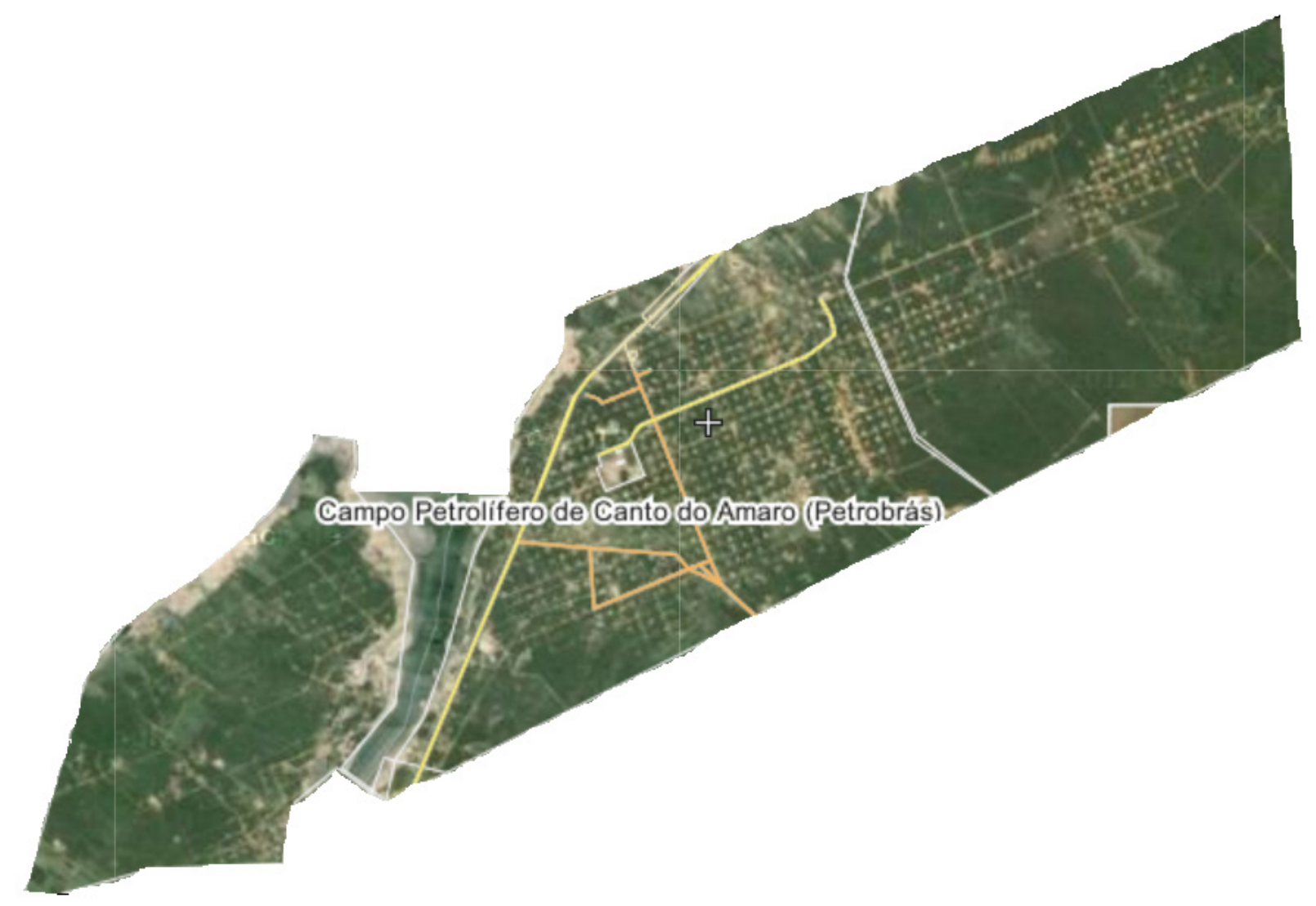

Foto 03: - Imagem Google Earth (Canto do Amaro) - mostra para toda a área, desenvolvimento de uma vegetação mais ou menos densa, com poucas áreas de solos expostos. 

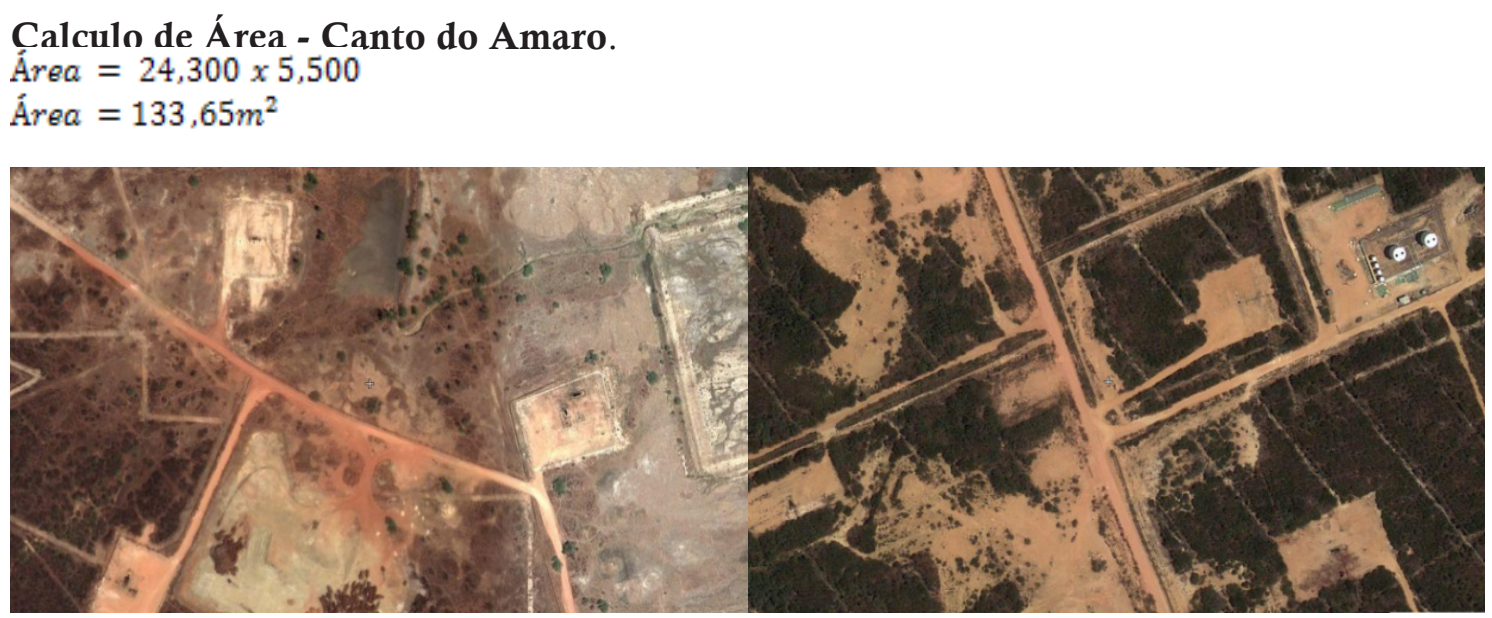

Foto 04: Imagem Google Earth (Canto do Amaro) - podemos observar pelas cores vermelho e cinza uma maior degradação do solo na região.

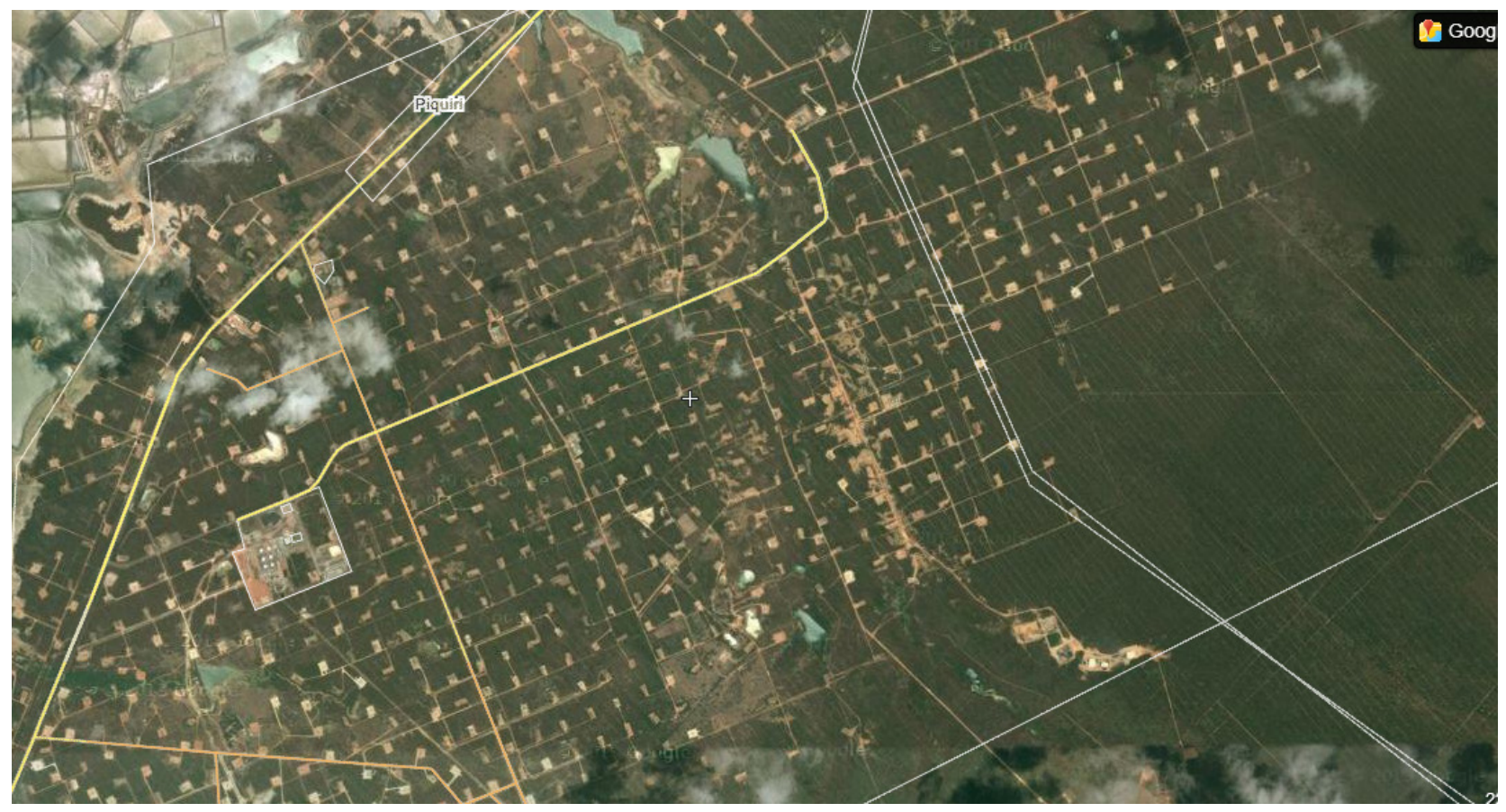

Foto 05: Imagem Google Earth (Canto do Amaro) - realçou as áreas de uso agrícola nos limites do campo Canto do Amaro, porém realçou um maior número de ocorrências de solos expostos.

\section{Calculo de Área - Poços de perfuração de petróleo}

$$
\begin{aligned}
& \text { Área }=\frac{B+b}{2} h \\
& \text { Área }=\frac{2822+1871}{2} 3600 \\
& \text { Área }=8,447 \mathrm{~m}^{2}
\end{aligned}
$$

A avaliação da área degradada por poços de petróleo foi realizada através da comparação dos resultados analíticos das amostras do mapeamento de 100 áreas de poços, para obter uma estimativa da degradação foi realizado cálculos para medir: Área, Media, Moda, Mediana, Desvio Padrão, Variância, Curtose e Assimetria. As Tabelas 1, 2 e 3 abaixo apresentam os resultados das amostragens. 


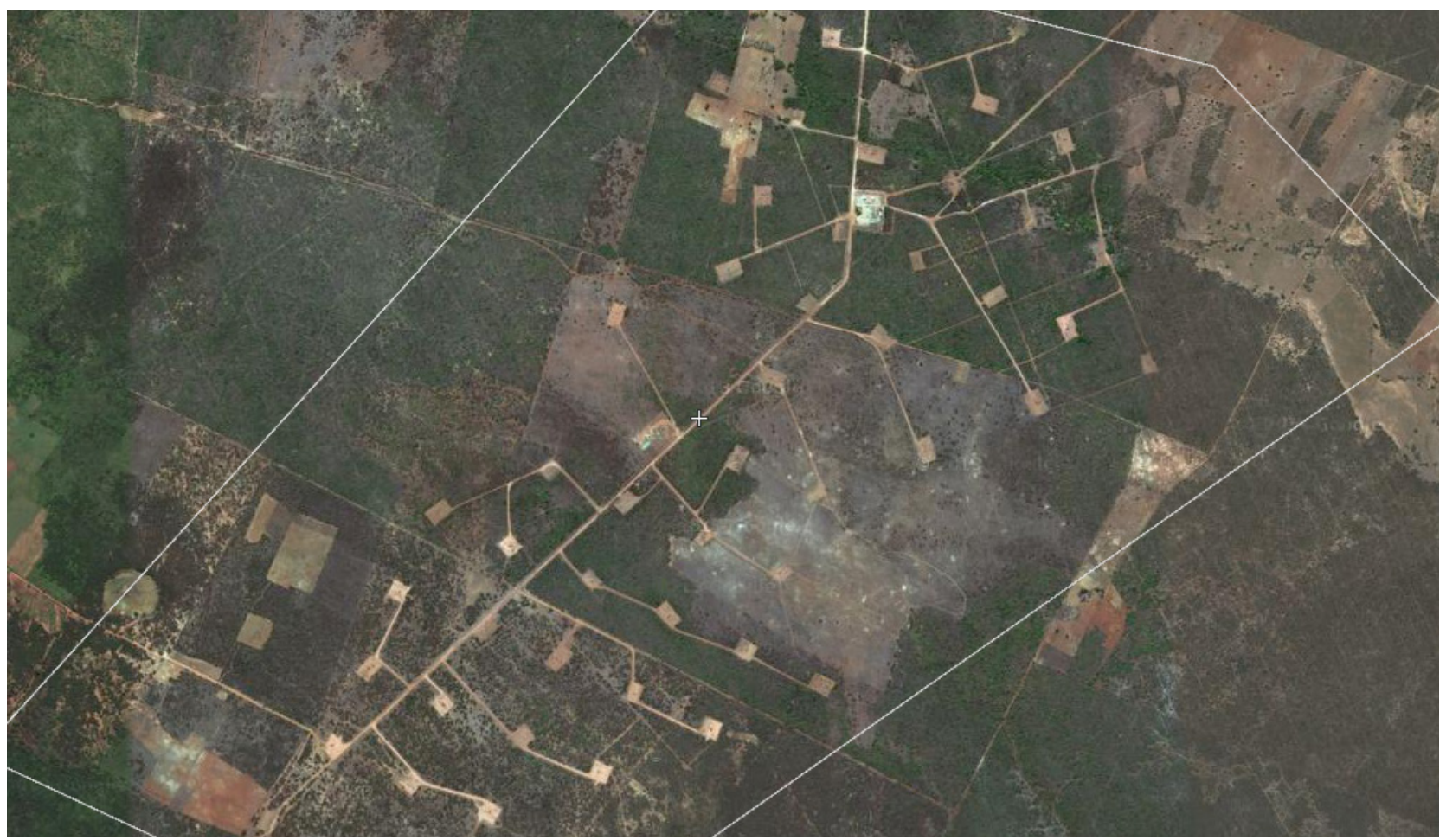

Foto 06: Imagem Google Earth (Poços de perfuração de petróleo) - realçou a localização dos poços, as estradas e áreas de erosão dos solos dentro do campo.

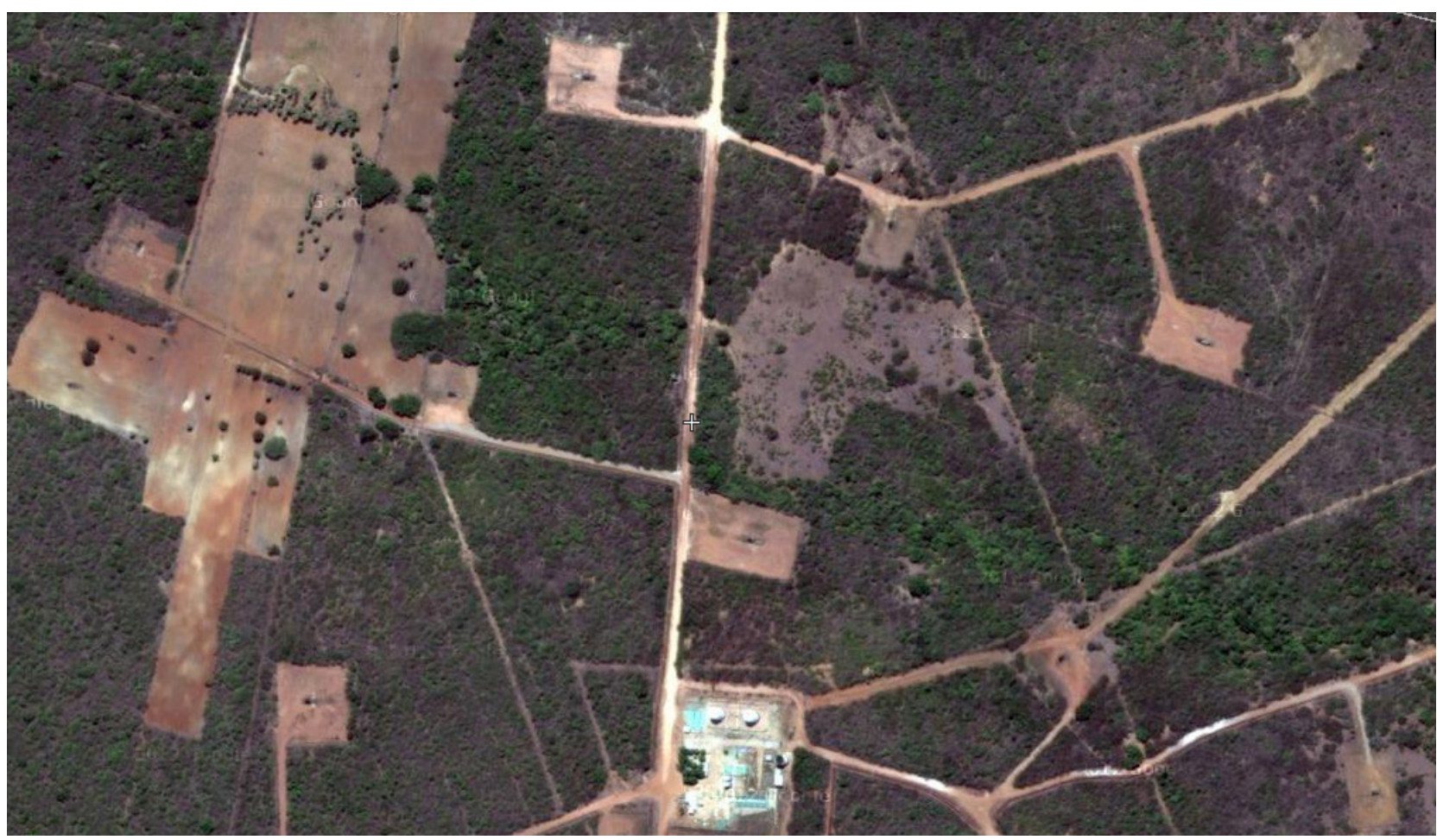

Foto 07: Imagem Google Earth (Poços de perfuração de petróleo) - realçou uma diferenciação da vegetação. 
Tabela 1: Cálculo das Áreas dos Poços de Petróleo em Mossoró - RN.

\begin{tabular}{|c|c|c|c|}
\hline \multirow[b]{2}{*}{ Poços } & \multicolumn{3}{|c|}{ Cálculo das Áreas dos Poços } \\
\hline & Área A (m) & Área B (m) & $\begin{array}{l}\text { Cálculo de } \\
\text { Área }\end{array}$ \\
\hline 1 & 75 & 57 & 4275 \\
\hline 2 & 57 & 62 & 3534 \\
\hline 3 & 54 & 52 & 2808 \\
\hline 4 & 59 & 45 & 2655 \\
\hline 5 & 49 & 54 & 2646 \\
\hline 6 & 38 & 60 & 2280 \\
\hline 7 & 51 & 86 & 4386 \\
\hline 8 & 58 & 44 & 2552 \\
\hline 9 & 80 & 45 & 3600 \\
\hline 10 & 60 & 56 & 3360 \\
\hline 11 & 77 & 58 & 4466 \\
\hline 12 & 54 & 58 & 3132 \\
\hline 13 & 39 & 55 & 2145 \\
\hline 14 & 54 & 58 & 3132 \\
\hline 15 & 43 & 60 & 2580 \\
\hline 16 & 79 & 55 & 4345 \\
\hline 17 & 84 & 47 & 3948 \\
\hline 18 & 49 & 81 & 3969 \\
\hline 19 & 55 & 81 & 4455 \\
\hline 20 & 56 & 81 & 4536 \\
\hline 21 & 70 & 47 & 3290 \\
\hline 22 & 41 & 65 & 2665 \\
\hline 23 & 54 & 76 & 4104 \\
\hline 24 & 78 & 58 & 4524 \\
\hline 25 & 60 & 57 & 3420 \\
\hline 26 & 55 & 64 & 3520 \\
\hline 27 & 83 & 50 & 4150 \\
\hline 28 & 44 & 76 & 3344 \\
\hline 29 & 56 & 52 & 2912 \\
\hline 30 & 49 & 77 & 3773 \\
\hline 31 & 54 & 54 & 2916 \\
\hline 32 & 229 & 139 & 31831 \\
\hline 33 & 84 & 99 & 8316 \\
\hline 34 & 43 & 87 & 3741 \\
\hline 35 & 88 & 57 & 5016 \\
\hline 36 & 57 & 78 & 4446 \\
\hline 37 & 81 & 48 & 3888 \\
\hline 38 & 41 & 75 & 3075 \\
\hline 39 & 84 & 48 & 4032 \\
\hline 40 & 80 & 50 & 4000 \\
\hline 41 & 37 & 68 & 2516 \\
\hline 42 & 50 & 55 & 2750 \\
\hline 43 & 64 & 56 & 3584 \\
\hline
\end{tabular}


Tabela 1: Continuação...

\begin{tabular}{|c|c|c|c|}
\hline \multirow[b]{2}{*}{ Poços } & \multicolumn{3}{|c|}{ Cálculo das Áreas dos Poços } \\
\hline & Área A (m) & Área B (m) & $\begin{array}{l}\text { Cálculo de } \\
\text { Área }\end{array}$ \\
\hline 44 & 41 & 55 & 2255 \\
\hline 45 & 57 & 55 & 3135 \\
\hline 46 & 79 & 46 & 3634 \\
\hline 47 & 58 & 61 & 3538 \\
\hline 48 & 78 & 43 & 3354 \\
\hline 49 & 34 & 63 & 2142 \\
\hline 50 & 40 & 57 & 2280 \\
\hline 51 & 42 & 78 & 3276 \\
\hline 52 & 38 & 57 & 2166 \\
\hline 53 & 53 & 58 & 3074 \\
\hline 54 & 57 & 79 & 4503 \\
\hline 55 & 42 & 58 & 2436 \\
\hline 56 & 74 & 43 & 3182 \\
\hline 57 & 50 & 62 & 3100 \\
\hline 58 & 39 & 78 & 3042 \\
\hline 59 & 53 & 57 & 3021 \\
\hline 60 & 79 & 42 & 3318 \\
\hline 61 & 52 & 80 & 4160 \\
\hline 62 & 36 & 63 & 2268 \\
\hline 63 & 36 & 55 & 1980 \\
\hline 64 & 37 & 78 & 2886 \\
\hline 65 & 52 & 66 & 3432 \\
\hline 66 & 33 & 60 & 1980 \\
\hline 67 & 36 & 59 & 2124 \\
\hline 68 & 59 & 53 & 3127 \\
\hline 69 & 45 & 83 & 3735 \\
\hline 70 & 38 & 64 & 2432 \\
\hline 71 & 40 & 74 & 2960 \\
\hline 72 & 31 & 52 & 1612 \\
\hline 73 & 38 & 90 & 3420 \\
\hline 74 & 44 & 77 & 3388 \\
\hline 75 & 56 & 72 & 4032 \\
\hline 76 & 45 & 85 & 3825 \\
\hline 77 & 39 & 60 & 2340 \\
\hline 78 & 44 & 87 & 3828 \\
\hline 79 & 52 & 53 & 2756 \\
\hline 80 & 42 & 75 & 3150 \\
\hline 81 & 35 & 63 & 2205 \\
\hline 82 & 35 & 55 & 1925 \\
\hline 83 & 44 & 65 & 2860 \\
\hline 84 & 36 & 68 & 2448 \\
\hline 85 & 30 & 78 & 2340 \\
\hline 86 & 38 & 52 & 1976 \\
\hline
\end{tabular}


Tabela 1: Continuação...

\begin{tabular}{cccc}
\hline & \multicolumn{3}{c}{ Cálculo das Áreas dos Poços } \\
\cline { 2 - 4 } Poços & Área A $(\mathbf{m})$ & Área B $(\mathbf{m})$ & $\begin{array}{c}\text { Cálculo de } \\
\text { Área }\end{array}$ \\
\hline 87 & 35 & 79 & 2765 \\
88 & 39 & 73 & 2847 \\
89 & 88 & 40 & 3520 \\
90 & 69 & 39 & 2691 \\
91 & 42 & 71 & 2982 \\
92 & 82 & 34 & 2788 \\
93 & 73 & 44 & 3212 \\
94 & 32 & 80 & 2560 \\
95 & 44 & 72 & 3168 \\
96 & 83 & 43 & 3569 \\
97 & 43 & 72 & 3096 \\
98 & 67 & 40 & 2680 \\
99 & 68 & 33 & 2244 \\
100 & 70 & 49 & 3430 \\
\hline
\end{tabular}

Tabela 2: Cálculos obtidos a partir dos valores das áreas.

\begin{tabular}{cccc}
\hline \multirow{2}{*}{ Média } & \multicolumn{3}{c}{ Tratamento Estatístico de Dados } \\
\cline { 2 - 4 } 3508 & Moda & Mediana & Desvio Padão \\
\hline \multirow{2}{*}{2280} & 3133,5 & 2997,2 \\
\hline
\end{tabular}

Tabela 3: Cálculos obtidos a partir dos valores das áreas.

\begin{tabular}{ccc}
\hline & \multicolumn{2}{c}{ Tratamento Estatístico de Dados } \\
\cline { 2 - 3 } Variância & Curtose & $\begin{array}{c}\text { Assimetria } \\
\text { (distorção) }\end{array}$ \\
\hline 8983260,6 & 82,56 & 8,72 \\
\hline
\end{tabular}

\section{CONCLUSÃO}

Os solos da região de Mossoró, de modo geral, oferecem condições razoáveis de produtividade agrícola, principalmente com o uso da irrigação. Os solos potencialmente produtivos encontram restrições, principalmente no déficit de água, e no grau de erosão.

Os Mapas apresentados no trabalho refletem a ação histórica do homem sobre a região, aonde vem ocorrendo um rápido avanço da ocupação da exploração de petróleo. Os manguezais, que há alguns anos atrás ocupavam todo o ambiente do rio Mossoró, foram praticamente arrancados para a implantação de áreas de exploração de petróleo.

O principal agente degradador das terras tem sido a exploração petrolífera. Áreas degradadas não foram recuperadas, e hoje representam um estágio avançado do processo da desertificação. Os níveis de degradação das terras encontradas neste trabalho estão bem expostos e deve ser dada uma especial atenção unas estratégias de recuperação destas áreas e de proteção do meio ambiente, que possibilite a exploração dos recursos naturais de modo sustentável, com diminuição dos riscos. 
Com relação aos processos de degradação das terras faz-se necessário que medidas sejam implantadas urgentemente, pois o processo está avançando, colocando em risco não somente as atividades agropecuárias da região, mas a própria infraestrutura de exploração.

\section{REFERÊNCIAS}

ANP, Pesquisa campo Canto Amaro Mossoró - RN - 2011. Disponível em: <https://www.google.com.br/ url? $\mathrm{sa}=\mathrm{t} \& \mathrm{rct}=\mathrm{j} \& \mathrm{q}=\& \mathrm{esrc}=\mathrm{s} \&$ source $=$ web $\& \mathrm{~cd}=3 \& \mathrm{ved}=0 \mathrm{CEYQFjAC} \& u r l=\mathrm{http} \% 3 \mathrm{~A} \% 2 \mathrm{~F} \% 2 \mathrm{Fwww}$.anp.gov. br\%2F\%3Fdw\%3D8419\&ei=TyN5UrGiFYXr2AWq0oDgAg\&usg=AFQjCNGFvpH-6A1wZzWgBnK23Zh_1 ywYAQ\&sig2=CNP-YFSfqoldkb9it9VzGw> Acesso em: 05 Nov. 2013.

2) CARVALHO; FELIPE; ROCHA, . Pesquisa áreas degradadas Mossoró - RN - 2011. Disponível em: $<$ https: $/ /$ www.google.com.br/url?sa $=$ t\&rct $=j \& q=\& e s r c=s \&$ source $=$ web $\& c d=2 \& c a d=$ rja\&ved $=0 \mathrm{CDcQFjAB}$ \&url=http $\% 3 \mathrm{~A} \% 2 \mathrm{~F} \% 2 \mathrm{Fpropi}$.ifto.edu.br\%2Focs\%2Findex.php $\% 2 \mathrm{~F}$ connepi $\% 2 \mathrm{Fvii} \% 2 \mathrm{Fpaper} \% 2 \mathrm{Fview} \% 2 \mathrm{~F} 40$ 33\%2F1754\&ei=1xR5Uob4J4mVqQHnj4FQ\&usg=AFQjCNGSXAMFAVkk9cfmWYuDtZ6vD-sgkw\&sig2= PrAr94KV1vriOJ7irNtOKA >. Acesso em: 04 Nov. 2013.

FABRIS; KOBIYAMA; MINELLA. Pesquisa áreas degradadas Mossoró - RN - 2011. Disponível em: < http://propi.ifto.edu.br/ocs/index.php/connepi/vii/paper/view/4033/1754>. Acesso em: 04 Nov. 2013.

TEÓDULO, Pesquisa áreas degradadas Mossoró - RN - 2011. Disponível em: < http://propi.ifto.edu.br/ocs/ index.php/connepi/vii/paper/view/4033/1754>. Acesso em: 04 Nov. 2013.

RIO GRANDE DO NORTE. Pesquisa economia de Mossoró - RN - 2005. Disponível em: <http://redeglobo.globo.com/globouniversidade/noticia/2011/06/sal-e-petroleo-impulsionam-economia-do-semiarido-nordestino.html> Acesso em: 04 Nov. 2013.

Caroline Faria, Pesquisa sobre aeromotometria, 2012. Disponível em: $<$ http://www.infoescola.com/cartografia/aerofotogrametria/> Acesso em: 04 Nov. 2013.

Pesquisa Google Earth - 2013. Disponível em: <https://support.google.com/earth/answer/176145?hl=pt-BR> Acesso em: 04 Nov. 2013.

Pesquisa ARCGIS - 2013. Disponível em: < http://www.img.com.br/solucaointegral/SitePages/ArcGIS\%20 Online \%20-\%20Vis\%C3\%A3o\%20Geral.aspx?Categoria=Sistema\%20ArcGIS > Acesso em: 04 Nov. 2013.

Antonio Costa, Pesquisa campo petrolífero Canto do Amaro - 2013. Disponível em: < http://www.dominiopublico.gov.br/pesquisa/DetalheObraForm.do?select_action=\&co_obra=104414 > Acesso em: 04 Nov. 2013.

Michel 2005, pág. 39 - Disponível em: < http://xxiiienangrad.enangrad.org.br/anaisenangrad/_resources/ media/artigos/gds/01.pdf> Acesso em: 05 Nov. 2013.

\section{Alan 2012, A EXPLORAÇÃO DO PETRÓLEO E A DINÂMICA TERRITORIAL NO MUNICÍPIO DE MOSSORÓ $-2012<$ https: / www.google.com.br/url? sa $=\mathrm{t} \& \mathrm{rct}=\mathrm{j} \& \mathrm{q}=\& \mathrm{esrc}=\mathrm{s} \&$ source $=$ web \&cd $=1 \& \mathrm{ved}=0 \mathrm{C}$ C8QFjAA\&url=http\%3A\%2F\%2Fwww.agb.org.br\%2Fevento\%2Fdownload.php\%3FidTrabalho\%3D2624\&ei =RAqNUs2eDI3msAS-y4CABQ\&usg=AFQjCNGmfq189sFVdiJSX5LXbWheylW0pg\&sig2=ehN2BQG8JL PW1cMiMZPiCA\&bvm=bv.56643336,d.cWc> Acesso em: 19 Nov. 2013.}

CORRÊA 1998, pág. 21. Disponível em: < http://site.ucdb.br/public/md-dissertacoes/8104-territorialidade-da-comunidade-de-pescadores-artesanais-praia-do-pereque-guaruja-sp.pdf> Acesso em: 19 Nov. 2013.

Andrade 1998, pág. 5 - Disponível em: < http://www.fesfsus.net.br/guiadotrabalhador/As\%20Diferentes\%20 Abordagens\%20do\%20Conceito\%20de\%20Territ\%C3\%B3rio.PDF > Acesso em: 19 Nov. 2013. 
ANDRADE, 1998, p. 220 - Disponível em: <http://www.ufpe.br/posgeografia/images/tesegeografia.pdf> Acesso em: 19 Nov. 2013.

Reinaldo A.Petta, 2007, Disponível em : <http://www.portalabpg.org.br/PDPetro/4/ resumos/4PDPETRO_6_2_0289-2.pdf> Acesso em: 19 Nov. 2013.

Antônio Costa 2007, Disponível em : < http://www.recursosnaturais.ufcg.edu.br/teses/AntonioCFilho_2007. pdf> Acesso em: 20 Nov. 2013. 